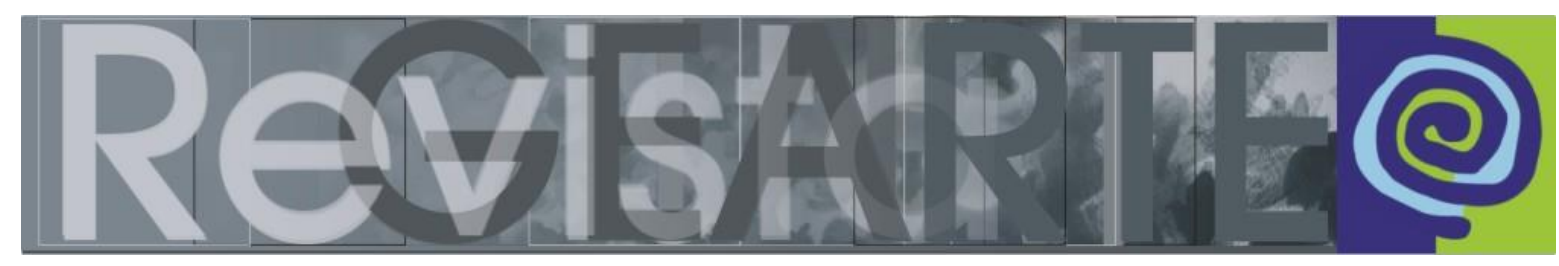

Volume 1, Número 2, Agosto/2014, ISSN 2357-9854

\title{
A origem de projetos educacionais nas Bienais de Arte de São Paulo ${ }^{1}$
}

\author{
José Minerini Neto (Pesquisador independente - Brasil)
}

\begin{abstract}
RESUMO
A educação nas Bienais de Arte de São Paulo surgiu porque o público visitante e a crítica de arte constataram que a I Bienal do Museu de Arte Moderna de São Paulo, em 1951, não havia organizado um projeto educacional para introduzir a arte moderna, especialmente a abstrata, aos brasileiros. Walter Zanini foi um dos críticos que destacaram esta falha, constatação presente entre os 10 mil estudantes que visitaram a mostra. Como reação imediata, foram realizadas palestras e encontros com organizadores da exposição e com comissários que acompanhavam as delegações dos países, chamadas representações nacionais, seguindo o formato da Bienal de Arte de Veneza, precursora das mostras bienais, referenciada pela Bienal de São Paulo. O primeiro projeto educacional da Bienal contou com monitores preparados em curso de História da Arte do Museu de Arte Moderna de São Paulo sob orientação do professor Wolfgang Pfeiffer. Os operários das indústrias e não os estudantes justificaram essa iniciativa, criticada posteriormente por Mário Pedrosa.
\end{abstract}

PALAVRAS-CHAVE

Educação; mediação; arte; Bienal de São Paulo; história.

\section{ABSTRACT}

Education in the São Paulo Art Biennial took place because the visiting public and art critics founded that the I Biennial of the Museum of Modern Art in São Paulo, in 1951, had not organized an educational project to introduce modern art, especially the abstract one, to Brazilians. Walter Zanini was one of the critics who have highlighted this failure, which was also identified among the 10.000 students who visited the exhibit. As an immediate action, lectures and meetings were organized involving the exhibition organizers and commissioners who accompanied the countries delegations, called national representations. The model followed was the Venice Biennial of Art, forerunner of biennial exhibitions and referenced by the São Paulo Art Biennial. The first educational project of the Biennial featured monitors prepared in a course of art history at the São Paulo Museum of Modern Art, under the orientation of Professor Wolfgang Pfeiffer. The workers of industries and not the students justified this initiative, subsequently criticized by Mario Pedrosa.

\section{KEYWORDS}

Education; mediation; art; São Paulo Biennial; history.

\section{A falha da I Bienal}

O Museu de Arte Moderna de São Paulo - MAM SP preocupou-se desde o início de suas atividades a oferecer palestras e cursos sobre arte moderna. As primeiras exposições modernistas em São Paulo, protagonizadas por Lasar Segall e Anita

\footnotetext{
1 Este artigo resulta de tese de doutorado referente à educação nas Bienais de Arte de São Paulo defendida na Escola de Comunicações de Artes da Universidade de São Paulo em agosto de 2014, sob orientação da Prof ${ }^{a}$. Dr ${ }^{\mathrm{a}}$ Ana Mae Barbosa e coorientação da Prof ${ }^{\mathrm{a}}$. PHD Juth M. Burton no Teachers College da Universidade de Columbia, com apoio da Coordenação de Aperfeiçoamento de Pessoal de Nível Superior (CAPES).
} 
Malfatti, pela Semana de Arte de Moderna e pelas ações da Sociedade Pró-Arte Moderna, pelo Grupo Santa Helena e por Flávio de Carvalho junto ao Clube dos Artistas Modernos, não deram conta de aproximar a arte abstrata dos embates e intentos vanguardistas presentes nestes marcos da modernização da arte no Brasil.

Coube ao MAM SP e à I Bienal de Arte de São Paulo encampar essa discussão porque apresentaram obras de arte abstratas ou com princípios abstracionistas que inquietaram visitantes, dentre os quais, os 10 mil estudantes (MODERNA, s/d) que visitaram a I Bienal em 1951.

Lourival Gomes Machado foi o diretor artístico dessa Bienal, dividindo a organização com Francisco Matarazzo Sobrinho (Ciccillo) e sua esposa, Yolanda Penteado. Fato é que Ciccillo e Yolanda esforçaram-se para atrair artistas representativos no panorama moderno e não dedicaram a mesma atenção para ações educacionais.

Por conta disso, coube a Gomes Machado organizar e proferir palestras e aos comissários que acompanhavam as delegações nacionais postarem-se nos espaços expositivos dos países que representavam para conduzir visitas comentadas. Estas chamavam-se "Passeios explicativos". Tais iniciativas foram soluções encontradas pelos organizadores para acolher os visitantes interessados em compreender o que é arte moderna e abstrata.

Lourival participou de debate na Escola de Sociologia e Política de São Paulo junto a Antonio Rubbo Miler, representante da referida escola, e a Edoardo Bizzari, diretor do Instituto Ítalo-brasileiro de São Paulo (PEREIRA, 1951). Mario Augusto Pinto era um dos estudantes presentes no debate e destacou:

Estive na Bienal durante nove horas - e o quadro que mais me impressionou foi ‘Dois Namorados Num Café'2. Por mais que procurasse entender o quadro, não consegui vislumbrar os dois namorados. Foi, para mim, uma decepção. (PEREIRA, 1951)

Vários dos estudantes:

\footnotetext{
${ }^{2}$ Trata-se de uma pintura de Roger Chastell, artista que integrou a representação da França na I Bienal e que foi contemplado com o prêmio internacional de pintura.
} 
[...] quiseram explicações sobre obras expostas na Bienal, especialmente a que leva o título de 'Gato Persa' e 'Composição número 6'. O diretor do Museu de Arte Moderna (Gomes Machado) deu os esclarecimentos dentro dos seus conhecimentos no assunto. Mas, pelo que observou a reportagem, as moças ficaram sem saber realmente, o significado do 'Gato Persa'3 e da 'Composição número 6'. Uma estudante depois da prolongada exposição do professor, que acreditava ter descortinado os horizontes para o curioso espirito da moça, tornou a perguntar: - 'Mas por que 'Gato Persa', se não vemos o gato? (PEREIRA, 1951)

O crítico de arte Mário Barata discursou na Casa dos Estudantes, o comissário da Grã Bretanha na sede da Sociedade Brasileira de Cultura Inglesa e o vicecomissário da Bienal de Veneza Marcos Valsecchim no Edifício Guilherme Guinle, sede do MAM SP e também do Museu de Arte de São Paulo - MASP. Por se tratar de novidade, nesse caso vale o que Steinberg (2004, p.246) afirma:

[...] a relação entre qualquer arte nova - enquanto nova - e o seu próprio momento; ou, invertendo a sentença: cada momento, durante os últimos cem anos, teve a sua própria arte ultrajante, de modo que cada geração, desde Courbet, teve uma experiência de desconforto em relação à arte moderna. $\mathrm{E}$ neste sentido seria inteiramente errado dizer que o espanto experimentado pelas pessoas em relação a um novo estilo não é importante, já que não dura muito. Na realidade, dura muito tempo: tem-nos acompanhado durante um século. (STEINBERG, 2004, p. 246)

Frente aos questionamentos trazidos pelos visitantes, à incompreensão manifesta e debatida nas palestras e mesas redondas e sem ter organizado uma equipe que pudesse orientar e monitorar o público presente, coube aos comissários conduzir visitas nos espaços destinados às obras dos artistas dos países que representavam. Denominados 'passeios explicativos' nos quais se explicava o que é arte moderna, é assim que surgem as primeiras ações educativas na Bienal de São Paulo.

Com dias e horários estabelecidos, quem se interessasse pelo assunto poderia ir até a exposição - montada em edifício provisoriamente adaptado no espaço do Salão de Baile do Boulevard do Parque Trianon ${ }^{4}$ - que seria recebido por comissários dispostos para explicar arte moderna. Assim foi divulgado:

\footnotetext{
${ }^{3}$ Escultura de Luciano Minguzzi.

${ }^{4}$ O edifício da I Bienal foi projetado por Luiz Saia e Eduardo Kneese de Mello. A expografia concebida por Jacob Ruchti e Miguel Forte delimitava espaços para cada representação nacional no interior dos quais os comissários receberam o público para os passeios explicativos. (HERBST, 2001, p. 122)
} 
Para melhor orientação do público no exame das obras expostas, têm sido organizados passeios explicativos nos quais os visitantes são acompanhados pelos explicadores. Depois da série de palestras realizadas pelo professor Marco Valsecchi na sala da Itália, o pintor Armando Balloni incumbiu-se, por sua vez, de acompanhar grupos amadores de arte através de diversos pavilhões, enquanto o professor Pfeiffer, encarregado da Sala da Alemanha, conduziu uma comitiva de alemães aqui residentes e particularmente interessados nas obras vindas de seu país. Dentro de breves dias terá lugar novo passeio explicativo, organizado pelo Instituto de Cultura Ítalo-brasileiro e que estará a cargo do prof. Bizzari, anunciando-se também que igual iniciativa tomará o prof. Moussineaux, da 'Aliance Française'. (CORREIO, 1951)

\section{Wolfgang Pfeiffer e a preparação de monitores para a II Bienal}

Raros foram os críticos de arte que perceberam a ausência de pessoas preparadas e disponíveis na exposição para explicar o que é arte moderna. Embora poucos, colaboraram com a posição assumida pelos estudantes. Walter Zanini relata que:

Faltou sem dúvida à Bienal uma organização mais eficiente, a fim de que tudo isso fosse explicado aos interessados e a fim de que pudesse o público de São Paulo aproveitar mais ampla e diretamente os seus ensinamentos. Todo esse público era um material humano profundamente vivo a ser trabalhado, orientado (OBRIST, 2009, p. 67).

A crítica de arte estava interessada em debater arte figurativa e arte abstrata:

Com as Bienais, o museu (MAM SP) realiza plenamente outra de suas vocações, a de 'detector de vanguardas', e acirra a 'discussão - iniciada com a mostra inaugural - entre arte figurativa e abstrata; essa era uma questão bastante nova', lembra Wolfgang Pfeiffer, comissário da Alemanha na $1^{\mathrm{a}}$ Bienal e diretor técnico do MAM a partir de 1952 (D'HORTA, 1995, p. 26).

O MAM SP ministra cursos desde sua fundação em 1948 e confirma:

[...] o papel do museu formador do público, assim ampliando os envolvidos com o moderno. Para tanto, incide em dois pontos fundamentais: educação e exposições. A existência de um corpo técnico fica restrita aos críticos na direção e professores para conferências e cursos. [...] Com tais preocupações, em dez anos (1948 a 1958) realiza quase cem conferências, cursos sistemáticos de história da arte com projeções, o que era uma novidade, realizados entre 1952 e 1958 e idealizados pelo professor Wolfgang Pfeiffer, período em que exerce a função de diretor técnico (LOURENÇO, 1999, p. 111).

Entre os passeios explicativos que conduziu na Sala da Alemanha da I Bienal e os cursos de História da Arte que ministrava no MAM SP, Wolfgang Pfeiffer se 
estabeleceu como o primeiro professor dos monitores da Bienal, cujo início das atividades se tornou notícia:

Têm início na próxima segunda-feira $(21 / 12 / 1953)$ os passeios explicativos dos monitores da II Bienal, especialmente treinados para este fim. É o seguinte o horário fixado: segunda-feira, 16 horas, Sala Kokoschka; 17 horas, Sala Munch; 18 horas, Sala Klee; 20 horas Sala Picasso. Terça-feira, 16 horas, Sala Hodler; 17 horas, sala Moore; 18 horas, Sala da Paisagem Brasileira; 20 horas, Sala Cubismo; 21 horas, Sala Mondrian; Quarta-feira, 16 horas, Sala Cubismo; 17 horas, Sala Munch, 18 horas, Sala Calder; 20 horas, Sala Moore; 21 horas, Sala Klee (FOLHA DA TARDE, 1953).

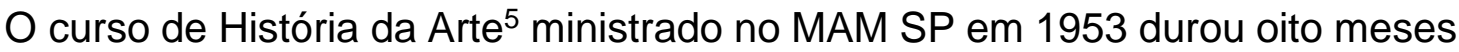

e:

[...] por seu turno, entre outras providencias, considerando a necessidade de conferências, cursos e folhetos elucidativos para mais ampla e profunda compreensão do público relativamente a exposições de arte moderna, resolveu criar um seminário para a formação de monitores que incumbirão da delicada tarefa de elucidação. Esse seminário, destinado à formação de monitores para a II Bienal constará de uma síntese de desenvolvimento da arte contemporânea e de suas diversas escolas e tendências. Estudos específicos sobre os artistas mais importantes e as teorias mais avançadas capacitarão os monitores a responder às perguntas que lhes forem formuladas. Na fase final da organização da II Bienal, entrarão em contacto (sic) com as obras a serem expostas, e quando a mostra for aberta ao público deverão organizar grupos para passeios explicativos. Esse curso deverá ser inaugurado ainda nesta quinzena. (FOLHA, não especificado)

A preparação dos monitores para a Bienal foi assunto amplamente destacado na imprensa. Em 1953, os jornais não só aclamavam os artistas estelares que participariam da II Bienal como também enalteciam o curso que preparava os "explicadores de arte moderna", os monitores, que conduziriam os passeios explicativos pela Bienal.

A Bienal foi concebida, organizada e montada pelo MAM SP até a sexta edição em 1961, contando em todas elas com a participação do Professor Wolfgang Pfeiffer. Mesmo com a origem da Fundação Bienal em 1962, que gerou o desligamento da mostra bianual com o referido museu, e após Ciccillo doar o acervo do referido museu

\footnotetext{
5 Pfeiffer dividia as aulas de História da Arte no MAM com os professores Benton e Oscar Campiglia. Em 1953 ele era diretor técnico do museu e ministrou dois cursos: um de História da Arte para alunos da Escola de Artesanato e interessados em geral que teve 200 alunos inscritos e outro específico para os monitores da Bienal. (ARTESANATO, s/d)
} 
para a USP no ano seguinte ${ }^{6}$, Pfeiffer continuou preparando os monitores até a VIII Bienal, em 1965.

\title{
Entre estudantes e operários
}

A intenção de melhor preparar e instruir as classes sociais populares ao introduzi-las no universo da arte moderna foi um dos argumentos que justificou a organização de Bienais de Arte em São Paulo. Enquanto os estudantes motivavam debates e passeios explicativos na I Bienal, não se estabeleceu como objeto de atenção educacional as crianças e nem os jovens escolares, mas sim os operários e trabalhadores das indústrias.

Anos depois, Mário Pedrosa escreveu que a industrialização de São Paulo fez com que, segundo o senso de 1950, a população da capital paulista chegasse a 1.754.000 de pessoas vivendo na cidade. Sessenta por cento $(60 \%)$ dessa população era composta por trabalhadores da indústria e prestadores de serviço das mais diversas ordens (PEDROSA, 1986, p. 253). Com isso, Pedrosa afirmou que uma das preocupações da Bienal, organizada por um empresário das indústrias (Ciccillo Matarazzo, por exemplo), era receber trabalhadores e operários de modo que pudessem se inserir nos meios culturais. O escritor Alcântara Silveira destacou:

\begin{abstract}
Se lá fora a Bienal tornará o nome do Brasil ainda mais em evidência, atestando o grau de nossa cultura artística, entre nós a exposição servirá para mostrar ao povo o que de mais adiantado e melhor existe atualmente, no mundo, nos domínios da arte. A bienal terá assim caráter eminentemente educativo, visando despertar no público não só interesse pela arte, como conhecimento mais amplo do movimento artístico mundial. Aliás, este tem sido o escopo principal do Museu de Arte Moderna que, graças a Francisco Matarazzo Sobrinho - seu incansável presidente - tudo tem feito pela educação artística das massas (SILVEIRA, 1952).
\end{abstract}

Silveira é evasivo e não identifica a qual público se refere, optando por usar a imprecisão das palavras povo e massa. Ao associar a análise de Pedrosa e o grande destaque dado à educação das massas, a Bienal não só tinha esse interesse, mas também poderia entreter e ocupar os trabalhadores de modo que houvesse a ação

\footnotetext{
${ }^{6}$ A Bienal tornou-se Instituição Pública em 1961 e Fundação em 1962, demonstrando que Ciccillo Matarazzo tinha mais interesse na Bienal do que no MAM. Em 1963 ele doou o acervo do museu para a USP que, por sua vez, criou o Museu de Arte Contemporânea da Universidade de São Paulo para abrigar a doação (ALAMBERT, CANHETE, 2004, p. 93-98).
} 
civilizatória da arte, colaborando de igual maneira com o apaziguamento dos movimentos reivindicatórios que tomavam força.

A intenção de educar o povo em arte também procurava livrar os organizadores da acusação de que promoviam eventos para eles próprios, a elite que - ao lado de Ciccillo Matarazzo e de Yolanda Penteado - corroborou, apoiou e aclamou a Bienal de São Paulo.

\section{Referências}

ALAMBERT, Francisco; CANHÊTE, Polyana Lopes. As Bienais de São Paulo: Da Era dos Museus à Era dos curadores (1951-2001). São Paulo: Boitempo, 2004.

ARTESANATO, Escola de. Relatório. São Paulo: Biblioteca Paulo Mendes de Almeida/Museu de Arte Moderna de São Paulo, sem data, sem paginação.

CORREIO Paulistano. Às segundas-feiras o ingresso à Bienal é gratuito. São Paulo: Correio Paulistano, 14/11/1951.

D’HORTA, Vera. MAM: Museu de Arte Moderna de São Paulo. São Paulo: DBA, 1995.

FOLHA (não especificado). Alcança projeção mundial o Museu de... . FOLHA (não especificado), 12/04/1953.

FOLHA da Tarde. Museu de Arte Moderna: Passeios explicativos dos monitores. São Paulo: Folha da Tarde, 18/12/1953.

HERBST, Hélio. Pelos salões da Bienal, a arquitetura ausente dos manuais: Contribuições para a historiografia Brasileira (1951-1959). São Paulo: Annablume, FAPESP, 2001.

LOURENÇO, Maria Cecília França. Museus Acolhem o Moderno. São Paulo: EDUSP, 1999.

MODERNA, Museu de Arte. Relatório da I Bienal. São Paulo: Arquivo Histórico Wanda Svevo da Fundação Bienal de São Paulo, s/d, inédito.

OBRIST, Hans Ulrich. Entrevista com Walter Zanini In. Entrevistas: Volume 1. Rio de Janeiro: Cobogó, Belo Horizonte: Inhotim, 2009.

PEDROSA, Mário. A Bienal de cá pra lá (1970). In: Paulo: Perspectiva, 1986. Mundo, homem, arte em crise. São

PEREIRA, J. Estudantes debatem a Bienal: Erro de tradução no quadro. São Paulo: Diário da Noite, $17 / 12 / 1951$.

SILVEIRA, Alcântara. Conversa sôbre (sic) a Bienal. Rio de Janeiro: Jornal de Letras, 07/1952.

STEINBERG, Leo. A arte contemporânea e a situação do seu público (1962). In: BATTCOCK, Gregory. A nova arte. São Paulo: Perspectiva, 2004.

\section{José Minerini Neto}

Doutor em Artes Visuais pela Escola de Comunicações e Artes da Universidade de São Paulo, mestre em Estética e História da Arte com licenciatura plena em Educação Artística e Desenho. Pesquisador independente, coordenador e professor da área de Arte na rede particular de ensino em São Paulo, cofundador do Arteducação Produções (AEP) e editor da revista eletrônica AEP Online.

E-mail: j.mneto@uol.com.br

Currículo: http://lattes.cnpq.br/6031242208088301 